The effect of modern intensified irradiation, which is often surprising in the cases of these immature tumour forms, makes the proper background for a more extensive ophthalmo-neurological diagnostication along the lines indicated here, which, when followed, will benefit the patients and reflect great credit on the doctors.

\title{
REFERENCES
}

GODTFREDSEN, ERIK.-Ophthalmological and neurological symptoms in malignant nasopharyngeal tumours. A clinical study comprising 454 cases. With special reference to histopathology and the possibility of earlier recognition. Acta Ophthal., Suppl. XXII, 1944; Acta Psych. and Neurol., Suppl. XXXIV, 1944 ; Acta Oto-Laryngol., Suppl. LIX, 1944 ; Acta Path and Microbiol. Sc., Suppl. LV, 1944 ; Diss., p. 320, 53 Fig., Munksgaard, Copenhagen, 1944.

\section{SOME RESEARCHES ON THE RESPIRATION OF THE CORNEA IN ALBINO RATS* $\dagger$}

BY

\section{A. BAKKER \\ GRONINGEN \\ Introduction}

IN studying literature dealing with the respiration of the cornea, we get the impression that our knowledge concerning this subject is rather defective. At any rate, we may say that the question whether the cornea uses the oxygen of the surrounding air is still far from settled.

Duke-Elder ${ }^{1}$ assumes that the cornea possesses a respiratory mechanism, whereby gases are actively transpired through the agency of the epithelium and the endothelium.

Bullot ${ }^{2}$, arguing on the grounds that in his experiments the endothelium of rabbits' eyes dies when the surrounding air is replaced by a mixture of 1 part air and 14 parts hydrogen, is of the opinion that the endothelium needs the oxygen from the surrounding air. This investigator placed the entire enucleated eyeball of the rabbit, with its epithelium scraped off, in an atmosphere of moist air at $35^{\circ} \mathrm{C}$. and observed that, after 15 hours, the endothelium was still living over the entire surface. When, however, the surrounding air was sufficiently rarefied with hydrogen (e.g., $1 / 15)$ it was established that after the same length of time all the endothelium cells were dead.

* From the Histological Institute, University Groningen, Director: Professor J. de Haan, M.D. † Received for publication, December 7, 1946. 
These facts certainly suggested the possibility that the endothelium uses the oxygen from the atmosphere, but as the experimental circumstances were far from physiological (the eyeballs being enucleated and the epithelium scraped off), these investigations do not determine whether also in the living animal the oxygen passes through the cornea from the air towards the anterior chamber.

Fischer $^{3}$ has carried out some experiments with the object of examining the respiration of the cornea. All his experiments were performed on rabbits. He constructed a small glass-bell, which was placed upon the luxated eyes of the animals. Thus by means of small tubes furnished with stopcocks, he could fill up the gaschamber of the apparatus with a definite gas, e.g., carbon dioxide or hydrogen with oxygen. At certain intervals gas-samples were taken out, in order to determine the consumption of oxygen or the production of carbon dioxide. His collective results were shown in a table. He compared among other things, for example, the respiration of a normal cornea with that of a cornea deprived of its layers of epithelium and endothelium. As to the $\mathrm{CO}_{2}$ production and the $\mathrm{O}_{2}$-consumption practically no difference could be noticed after one hour between the normal and the abnormal cornea; whereas after four hours the $\mathrm{CO}_{2}$-production was the same for both corneae, the $\mathrm{O}_{2}$-consumption, however, of the normal cornea was about 60 per cent. greater than the consumption of the abnormal cornea. So his results showed inexplicable irregularities. From these indeterminate results Fischer derives far-reaching conclusions. This investigator assumes that the cornea forms a barrier to the permeation of $\mathrm{O}_{2}$ and $\mathrm{CO}_{2}$ only in one direction, the oxygen being able to travel only backwards through the cornea from the air towards the anterior chamber, the carbon dioxide being able to pass the cornea only in the opposite direction. When Fischer filled up the glass-bell with 100 per cent. $\mathrm{CO}_{2}$, he observed that this had a deleterious effect on the cornea within one to two hours. The corneae became totally opaque. Taking into account his view that the cornea is permeable for $\mathrm{CO}_{2}$ only in one direction, it was obvious that he imputed the injurious influence of this gas to the impediment of the normal permeation of $\mathrm{CO}_{2}$ through the cornea from behind towards the surrounding atmosphere. As this selective permeability of the cornea for $\mathrm{CO}_{2}$ however, is by no means certain, Fischer's conclusion, based on this property also lacks reasonable ground.

I got the impression that in Fischer's experiment it was not the normal respiration of the cornea which was measured. In the first place, we notice that the glass-bell was compressed air-tight to the eyeball. In doing this, we cannot expect the normal circulation in the blood vessels of the eyeball to go on without any disturbance 
and naturally a change in the respiration of the cornea will be caused by any impediment in that circulation. In the second place, we may ask whether Fischer succeeded in measuring only the respiration of the cornea. Was it possible to exclude any influence of the blood in the surrounding limbus-vessels? And thirdly we must remark that the investigations were carried out on luxated eyeballs. Here too we have a factor which interferes with a normal circulation.

I have therefore thought it worth while to reinvestigate the question of the selective permeability of the cornea. A quite different line of research was started by my experiments.

The anaesthetised experimental animals (albino rats) were put into a closed space in an atmosphere of nitrogen or carbon dioxide or a mixture of these two gases. Of course artificial breathing was necessary to keep the animals alive. The object of these investigations was to examine if any injury of the cornea could be shown under the influence of these gases. We must draw attention to the fact that in my experiments the circulation of the eyes remained under absolutely physiological circumstances (the possible influence of the narcosis we may neglect). The arrangement of my experiments did not allow the measuring of the consumption of oxygen or the production of carbon dioxide, but it was pre-eminently suitable for studying the influence of different gases on normal eyes in situ. After an exposure of the eyes to the above mentioned gases for several hours, the animals were killed and the eyes were microscopically examined.

Before stating the results of the experiments we will first give a detailed description of the apparatus used.

A thick walled glass tank (accumulator tank), open at one side and measuring 11 by 14 by $24 \mathrm{~cm}$., was made air-tight by a copper plate (frontplate $\mathrm{A}$ in Fig. 1 and $\mathrm{A}^{\prime}$ in Fig. 2) with the aid of a rubber packing. This front-plate was held in position by two u-shaped frames and two strips of copper (one of each is shown in Fig. 5) and thus a closed space was obtained, in which the animals remained throughout the experiments. It is desirable to use a tank made of glass in order to be able to watch the animal in the course of the experiment.

Near the lower edge of the frontplate and parallel to this a horizontal metal plate is soldered ( $\mathrm{H}^{\prime}$ Fig. 2). At the back end of this plate are two small knobs on which it rests upon the bottom of the tank, when the frontplate is mounted. The object of this plate is to support a, let us say, small operation table (Fig. 4), on which the animals are tied. This operation table is attached by its metal strips $\left(\mathrm{L}^{\prime}\right)$ to the horizontal plate with the help of four clips. 


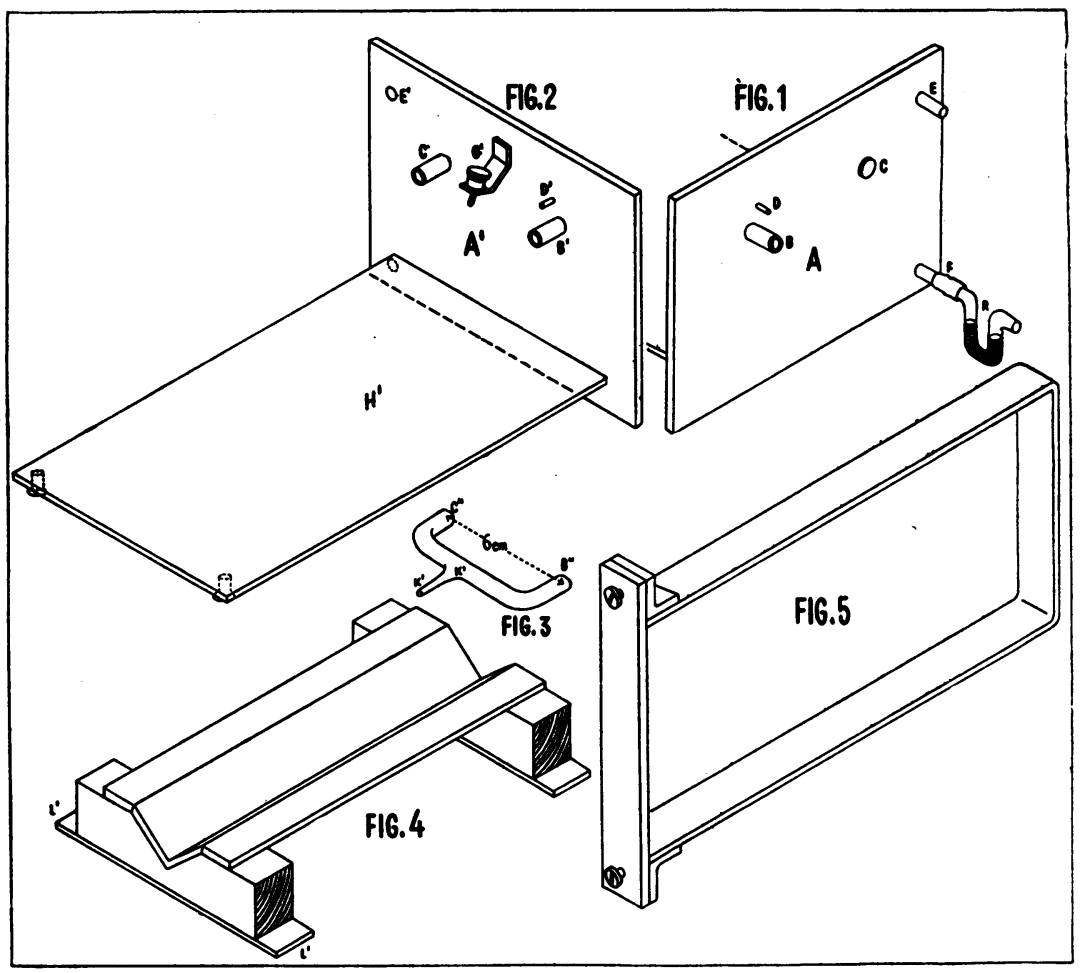

The frontplate is pierced by 5 copper tubes. The parts of these tubes inside the tank are indicated in the diagrams by an accented letter, the corresponding end outside the tank by the same letter non-accented. $\mathrm{BB}^{\prime}$ and $\mathrm{CC}^{\prime}$ have a bore of $6 \mathrm{~mm}$. $\mathrm{B}^{\prime}$ and $\mathrm{C}^{\prime}$ are connected by rubber.tubing to the trachea cannula. This consists of a right angled curved glass tube $\left(\mathrm{B}^{\prime \prime} \mathrm{C}^{\prime \prime}\right.$ Fig. 3 ) with a small side-tube $\mathrm{K}^{\prime} \mathrm{K}^{\prime}$ (the trachea cannula proper). $\mathrm{B}$ is connected with a small airpump during the course of the experiment. This pump provides a continual air current from B to C. After the animals have been anaesthetised by an injection of a $\frac{1}{2}$ per cent. solution of amytal sodium and after they have been tied on the operation table, the skin in front of the neck is cut through in the median line and, the muscles having been pulled aside, the trachea is brought into view, covered by the deep cervical fascia. The trachea is opened and the trachea cannula is inserted into it. $B^{\prime \prime}$ is connected with $B^{\prime}$ and $C^{\prime \prime}$ with $C^{\prime}$. Care must be taken not to injure the mucosa or the blood vessels, as the smallest amount of liquid would clog the cannula, causing death by suffocation. If the operation is carefully performed the animals can be kept alive for many hours. By means of the adjusting screw $\mathrm{G}^{\prime}$, resting 
upon the glass tube, the trachea cannula $\mathrm{K}^{\prime} \mathrm{K}^{\prime}$ can be inclined in any definite way, so that traction of the trachea is avoided. The volume of air between $B^{\prime \prime}$ and $C^{\prime \prime}$ is used as a source from which the animal inhales its oxygen and into which it exhales. It may be asked if it would not be simpler to connect the trachea cannula $\mathrm{K}^{\prime} \mathrm{K}^{\prime}$ by means of a lengthening-tube direct with the open air, without using an airpump. This, however, is impossible, as such a narrow cannula would be too long, whereby the resistance, offered to inspiration and to expiration would become too strong.

The small tube $\mathrm{DD}^{\prime}$, with a bore of $1 \frac{1}{2} \mathrm{~mm}$., is connected at its one end $D^{\prime}$ by valve tubing to an injection needle and at its other end $\mathrm{D}$ with a syringe. Before closing the tank, the syringe, tubing and needle are filled with the anaesthetising solution and the needle is inserted under the skin of the rat. In this way it is possible to give an in jection now and then during the course of the experiment, and thus the experimental animals can be kept continually under narcosis for many hours.

By a few sutures the eyelids are prevented from closing. Thus the eyes are fully exposed to the gas under investigation.

A small piece of iron is held against the inner side of the upper tank wall by a magnet outside the tank. By moving the magnet this piece of iron inside the tank can also be moved. This is very

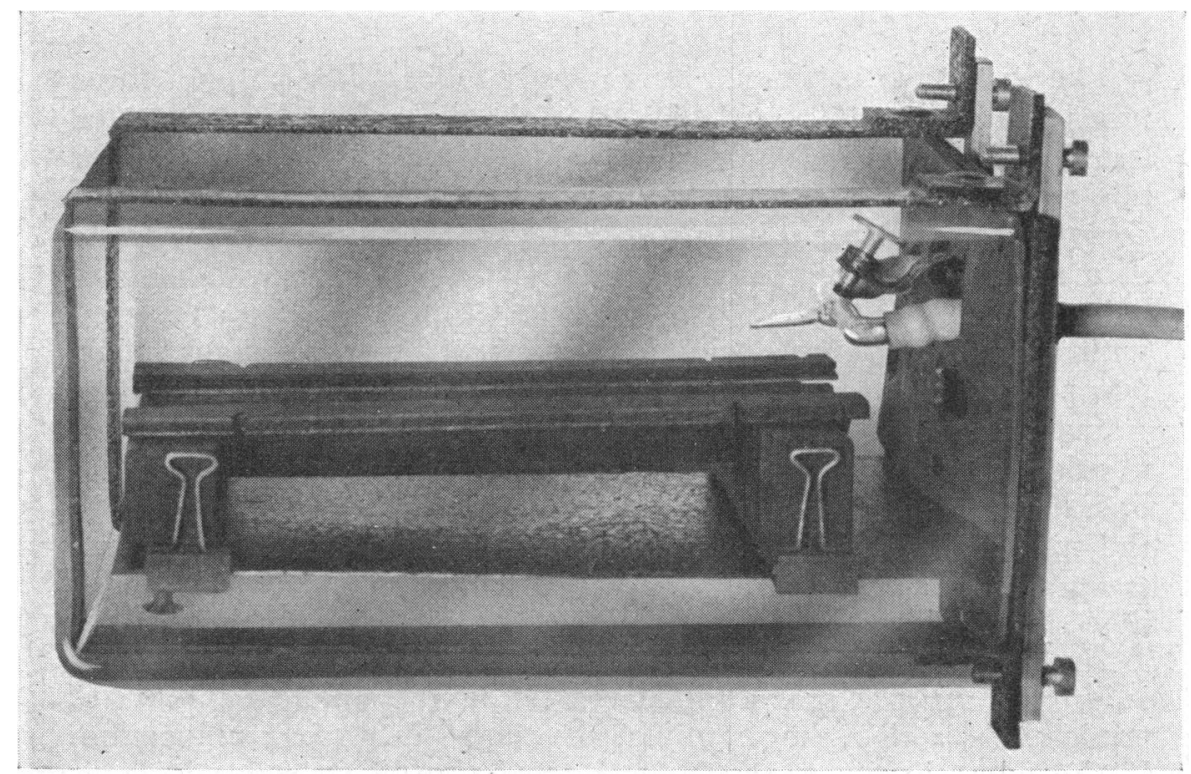

FIG. 6. 
convenient, as it wipes away the condensed water vapour from the inner glass wall, thereby facilitating looking into the tank.

Now the frontplate is brought into its position and the horizontal plate with its operation table and experimental animal is pushed into the tank. The frontplate is closed air-tight by means of the two frames and the airpump is immediately put into action. A photo of the whole apparatus (Fig. 6) elucidates the relation of the different parts in their normal position.

As it is very difficult to drive the air out of a tank by a gas, e.g., nitrogen, and as it is not easy to tell when the moment has arrived that the air is fully replaced by such a gas, I used another method, which allowed the filling of the tank within a short time with the desired gas or gas-mixture in a reliable way.

The copper tube $\mathrm{F}$ near the bottom of the tank in the frontplate is connected by rubber tubing to a u-shaped glass tube $\mathrm{R}$. This is the inlet for a 1 per cent. $\mathrm{NaCl}$-solution, previously saturated with the desired gas. The tank is completely filled up with the saline, while the air escapes through the open stopcock in tube $E$ near the upper edge of the frontplate.

When the tank is nearly full of the salt solution, the breathing of the animal is interfered with, as water is little compressible. Therefore we must act very quickly. At the same moment that the tank is fully filled up with the solution, the gas under investigation is let in through tube $\mathrm{E}$, while the salt solution can flow. away through tube $F$. When the water has fallen so far that the level stands in the upper part of both the legs of the u-shaped tube R, the stopcock in $\mathrm{E}$ is closed. In this way we have achieved our object of filling up the tank quickly with a definite gas.

We may neglect the influence of the vapour-tension of the water, as diminishing the tension of the gas under investigation.

The operation on the experimental animals and all the further manipulations until the end of the experiment, were performed in a room at a temperature of $37^{\circ} \mathrm{C}$.

\section{Description of the results}

The albino rats used had an average weight of 180 to $200 \mathrm{grs}$. They were anaesthetized by a subcutaneous injection of 4 c.c. of a 0.5 per cent. solution of amytal sodium in aqua dest. After about 20 minutes the narcosis generally was complete. Every two to three hours 1 or $\frac{1}{2}$ c.c. of the solution was injected in order to keep the animals under narcosis. The next quantum of the narcotic was generally given when the animals showed some signs of reawakening, for instance when just perceivable contractions in the legs were visible. It is clear that this made it necessary to watch the animals constantly. A good indicator for judging if the respiration of the animal is going on normally is the pink colour of 
the tail. The slightest disturbance in the respiration betrays itself by cyanosis of the tail.

The gas being saturated with water-vapour, the eyes will be protected from desiccation, though lacking the normal blinking of the eyelids.

In the first place my experiments had the object of investigating whether absence of oxygen in the atmosphere would cause any pathological changes in the cornea.

I obtained results similar to Fischer in so far that I could show that normal life of the cornea is possible in the absence of oxygen. After a stay of 12 hours in an atmosphere of pure nitrogen, the corneae remained quite clear and microscopically no injurious influence was found. In fact we could hardly have expected anything else. I only need to point to the fact that a whale can remain under water for some hours, that is in a medium with a very low concentration of oxygen, to understand that, besides the oxygen normally supplied by the blood vessels in the eye, the cornea does not need any other source of oxygen to preserve its integrity. If the normal respiration of the cornea depended on the oxygen content of the surrounding air the eyes would certainly get into a precarious position during sleep, when the eyes are hidden behind the closed eyelids. Altogether we may say that the evidence points to the fact that in normal circumstances the cornea does not use the oxygen from the surrounding atmosphere.

In order to investigate the influence of $\mathrm{CO}_{2}$ on the cornea, in the first place some experiments were carried out on rats in an atmosphere of pure carbon dioxide. Within half an hour the corneae became totally opaque. Consequently the deleterious effect of $\mathrm{CO}_{2}$ is obvious. The results of these experiments agree with those of Fischer. From such evidence alone, however, it could not be argued that it was an impediment in the normal permeation of $\mathrm{CO}_{2}$ through the cornea from behind towards the air which caused this injurious effect. On the contrary, the probability was great that the high concentration of $\mathrm{CO}_{2}$, being far from physiological, was the direct cause of the death of the corneal tissues.

It is clear that as Fischer's experiments were not carried out under physiological conditions, they did not prove the selective permeability of the normal cornea. Moreover, such a selective permeability in other animal membranes is still quite unsettled, e.g., Wertheim's experiments showing the permeability of $\mathrm{NaCl}$ through the frog's skin only in one direction could not be reproduced.

Even my own experiments cannot give a definite answer to the question whether a selective permeability of the cornea exists or not. Yet they have made this assumption very improbable. The following experiments show that a stay of several hours in a $\mathrm{CO}_{2}$ 
concentration, higher than any normal $\mathrm{CO}_{2}$ concentration in the body ( 8 per cent.), does not cause any pathological changes in the cornea.

Assuming that carbon dioxide normally diffuses away through the cornea from the anterior chamber towards the surrounding atmosphere, and assuming with $\mathrm{Kronfeld}^{4}$ that the $\mathrm{CO}_{2}$-tension in the aqueous humour lies between the $\mathrm{CO}_{2}$-tension of the venous blood and the arterial blood, we may be certain that a concentration of 8 per cent. of carbon dioxide outside the eye is high enough to impede the eventual permeation of $\mathrm{CO}_{2}$ through the cornea.

This concentration, being not far above the normal $\mathrm{CO}_{2}$-tension in the tissues, has the advantage of being almost physiological and it is not to be expected that it will have a direct noxious influence upon the cornea.

Some introductory experiments showed us that after two hours in an atmosphere of 8 per cent. of $\mathrm{CO}_{2}$ and 92 per cent. of nitrogen the corneae remained fully transparent. When we compare this with the injurious effect of 100 per cent. of $\mathrm{CO}_{2}$, causing the death of the corneal tissues within half an hour, we notice a striking difference. It goes without saying that the conception that the deleterious effect of $\mathrm{CO}_{2}$ is caused by an impediment of the permeation of $\mathrm{CO}_{2}$ through the cornea towards the exterior air, must now be rejected.

Repeated observations under the same circumstances as to the $\mathrm{CO}_{2}$-concentration ( 8 per cent.), but after more prolonged times (10 hours and more) have shown that no pathological changes were caused in the cornea. Histological investigation showed us that the corneae were normal in every respect. In one section sometimes 16 karyokinetic figures were seen in the deep layer of the corneal epithelium. This means that in such a cornea a few thousands of cell divisions occurred simultaneously. We could hardly wish for a more convincing proof of the integrity of the cornea. At first I. was of the opinion that this large number of cell divisions was abnormally high, and that it was the consequence of an irritating action of the $\mathrm{CO}_{2}$-gas. ${ }^{5}$ However, on counting the cell divisions in a cornea of normal rats of the same age, the number of mitoses found here, was not considerably lower than in the cornea of the experimental animal. Thus we may conclude that also in this respect the cornea of the experimental animals does not show any abnormality.

Since my experiments have shown that it is impossible to accept a noxious effect of one or other factor causing an impediment to the hypothetical normal diffusion of the carbon dioxide through the cornea towards the exterior air, we must give an explanation of the deleterious influence of high concentrations of this gas (e.g., 100 per cent. of $\mathrm{CO}_{2}$ ). I believe that we must assume a direct 
noxious influence of the $\mathrm{CO}_{2}$ causing rapidly the death of the whole cornea. In other words, I am of the opinion that carbon dioxide is able to permeate through the cornea from the surrounding atmosphere towards the anterior chamber, the possibility of which Fischer denies.

\title{
Summary
}

In this paper I have given a description of some experiments which had the object of studying the influence of various concentrations of $\mathrm{CO}_{2}$ and the absence of oxygen in the surrounding atmosphere on the cornea of anaesthetised albino rats. With the help of artificial breathing it was possible to close up the animals in a tank filled up with one kind of gas or another, and in this way to expose the eyes of the experimental animals under otherwise normal conditions to the gas under investigation. It could be determined that the so-called selectivepermeation of carbon dioxide through the cornea is not probable. Absence of oxygen in the surrounding atmosphere does not inhibit normal life of the cornea. The corneae remained transparent for many hours in an atmosphere of 8 per cent. of carbon dioxide and 92 per cent. of nitrogen. Special attention was paid to possible pathological changes in the corneae after the experiments were finished.

\section{REFERENCES}

1. DUKE-ELDER.-Text-book of Ophthalmology.

2. Bullot, G.-Jl. of Physiol., Vol. XXXI, p. 359, 1904.

3. FisCher, F. P.-Arch. f. Augenheilk., Vol. CII, p. 146, 1930.

4. KRONFELD.-Arch. f. Ophthal., Vol. CXVIII, p. 606, 1927.

5. BAKKER, A.-Ned. Tydschr. Geneesk., Vol. LXXXV, p. 1121, 1941.

\section{CONTRIBUTIONS TO TOTAL BLEPHAROPLASTY*†}

\author{
BY \\ IDA CZUKRÁSZ \\ DEBRECEN, HUNGARY
}

THE substitutions of deficiency of the whole lid is one of the great problems in plastic ophthalmic surgery and more so, if the upper lid is absent. There have been several methods published, recommended and employed. Here I want to show three different inethods of restoration-better to say substitute-for upper lid loss, providing suitable outer and inner layer at the same time.

CASE 1 (Fig. 1). The left upper lid of a lady aged 60 years was

* Received for publication, November 15, 1946.

† Report from the University Eye Clinic, Debrecen. Leader : Professor Kettesy. 